\title{
The medium-term aftermarket in high-tech IPOs: Patterns and implications
}

\author{
Sanjiv Jaggia Satish Thosar
}

\begin{abstract}
A number of theoretical models, loosely characterized under the rubric of behavioral finance, suggest that price convergence to value is far from instantaneous and possibly involves interplay between noise and informed traders. These models are motivated by documented anomalous patterns in equity markets and assume some form of psychological bias that affects investor behavior. With the benefit of hindsight it seems clear that the technology sector went through a bubble-like pattern in the late 1990s and that investor biases (if indeed they exist and can be inferred) may have been even more pronounced. Accordingly, our study focuses on the medium-term aftermarket in high-tech US IPOs during this period. Using both ordered logit regression and split-population hazard modeling approaches, we document momentum and reversal patterns that are consistent with the predictions of some behavioral finance models. Our findings indicate that momentum variables are important while fundamental variables have at best weak explanatory power.
\end{abstract}

JEL classification: G14; C41

Keywords: Investor psychology; Technology bubble; Momentum; Underwriter reputation

\section{Introduction}

A number of empirical studies relating to IPOs have documented two persistent so-called anomalies: the initial underpricing and the long-run underperformance of 
IPO firms. These patterns have been documented in various markets and sample periods. ${ }^{1}$ The theoretical work has mainly attempted to explain the initial underpricing phenomenon. ${ }^{2}$ Some researchers have argued that the long-run underperformance of IPO firms is not a true anomaly and that the results are sensitive to the way in which long-term returns are calculated. ${ }^{3}$ Regardless of whether the long-run performance of IPO firms is inferior to or about the same as a control group, there is little doubt that the empirical IPO literature suggests significant initial price momentum and a relatively slow convergence to value.

As a parallel development, the capital markets literature now embraces a more complex view of price discovery. A number of theoretical models, loosely characterized under the rubric of behavioral finance, suggest that price convergence to value is far from instantaneous (or even guaranteed) and possibly involves interplay between noise and informed traders. ${ }^{4}$ Most of these models were developed as theoretical underpinnings to the mounting empirical literature on capital market anomalies that challenged one of the bulwarks of modern finance: the efficient markets hypothesis. However, the issue is far from settled and the debate continues. ${ }^{5}$

Many securities markets appear to exhibit short-run momentum and long-run reversals. ${ }^{6}$ The theories that have emerged to explain this pattern have relied on one or more forms of psychological biases that seemingly influence investor behavior. For instance, Daniel et al. (1998), hereafter referred to as DHS, theorize that investor overconfidence causes overreaction to private signals, undue self-attribution bias ${ }^{7}$ induces the overreaction to continue in the short-run, while the long-run reversal is necessarily implied by the initial overreaction.

In our opinion, the overheated high-tech IPO environment of the late 1990s is an ideal testing ground of the DHS and possibly other behavioral theories. The initial underpricing of IPOs is likely to be even more pronounced for the high-tech subset and an appropriate examination of the aftermarket will uncover momentum and reversal patterns if they exist. Focusing on high-tech IPOs rather than including all technology companies (or simply looking at a market index) has the advantage of a defined starting point for each firm in the sample. Also, we thought it likely that studying the IPO aftermarket has the potential to reveal momentum and/or reversal patterns in months rather than years. In other words, our approach may uncover patterns implied by behavioral finance models like DHS in sharp relief and over a

\footnotetext{
${ }^{1}$ See Loughran et al. (1994) for a survey of the international evidence. Also see Jain and Kini (1994), Lee et al. (1996) and Loughran and Ritter (1995).

${ }^{2}$ See Rock (1986), Welch (1989), Grinblatt and Hwang (1989), Benveniste and Spindt (1989) and Loughran and Ritter (2002a).

${ }^{3}$ See Brav and Gompers (1997).

${ }^{4}$ See Lee (2001) for a stimulating opinion piece on capital market efficiency and Daniel et al. (2001) for examples of behavioral finance models.

${ }^{5}$ See Fama (1998) and Rubinstein (2001) for critiques of the anomalies and behavioral finance literatures.

${ }^{6}$ See Fama and French (1988) and Poterba and Summers (1988) among others.

${ }^{7}$ Investors subject to self-attribution bias interpret validating public signals as confirmation of their ability while contrary signals are discounted.
} 
collapsed time period. While the results may not be completely generalizable to a wider sample, we think the benefits of our sample choice outweigh the limitations.

It should be noted that an examination of aftermarket patterns cannot be a direct test of a particular behavioral finance model. We have chosen to highlight DHS because the overconfidence and self-attribution biases appear to ring true in the context of the previously documented IPO anomalies. Other theories such as those proposed by Shiller (1984), Barberis et al. (1998) or Hong and Stein (1999) make plausible assumptions about investor behavior and possibly could apply just as well.

Specifically, we examine the medium-term (6-month) aftermarket in high-tech US

IPOs launched in the late 1990s. We assume the perspective of an investor who has no preferential allotment and has access only to easily available and virtually costless information in the public domain. As explained above, the sample is deliberately narrowly drawn. Our high-tech IPO firms fall primarily in the following sectors: computer hardware/software, e-commerce, telecommunications and biotechnology. Clearly, these sectors are perceived to have huge potential for future growth and profitability but individual firms and their investors face considerable uncertainty about the viability of their technology and/or business models.

We first employ an ordered logit regression (OLR) approach, which involves setting up a hierarchy of thresholds of post-IPO market-adjusted returns - this is loosely in the spirit of investor determined price targets. We find that fundamental variables like pre-IPO profitability and age of the company have weak influence at best in explaining post-IPO returns. The aftermarket is driven almost entirely by momentum variables. We also document post-IPO overreaction and reversal patterns consistent with the DHS theory. In order to ensure that the results are robust to an alternative estimation procedure, we also implement a split-population hazard (SPH) modeling approach. This yields results broadly consistent with those from the OLR. In Section 2, we outline the research hypotheses and describe the sample and variables used in the study. Section 3 contains a discussion of the OLR method and results. The SPH procedure and results are described in Section 4. The final section contains concluding comments.

\section{Research hypotheses, sample and variable descriptions}

\subsection{Research hypotheses}

The essence of the DHS theory in an IPO aftermarket framework is shown in Fig. 1. Given a favorable private signal, investor overconfidence pushes the stock price above its rational expected level at time 1. (In the context of our application, this would represent Day 1 IPO underpricing.) If public signals are perceived as confirming the initial private assessment, self-attribution bias drives the price even higher and further away from the rational level at time 2 (short-run positive momentum in the IPO aftermarket). The arrival of further public information gradually induces the price back toward the fundamental level at time 3 and beyond (reversal of the 


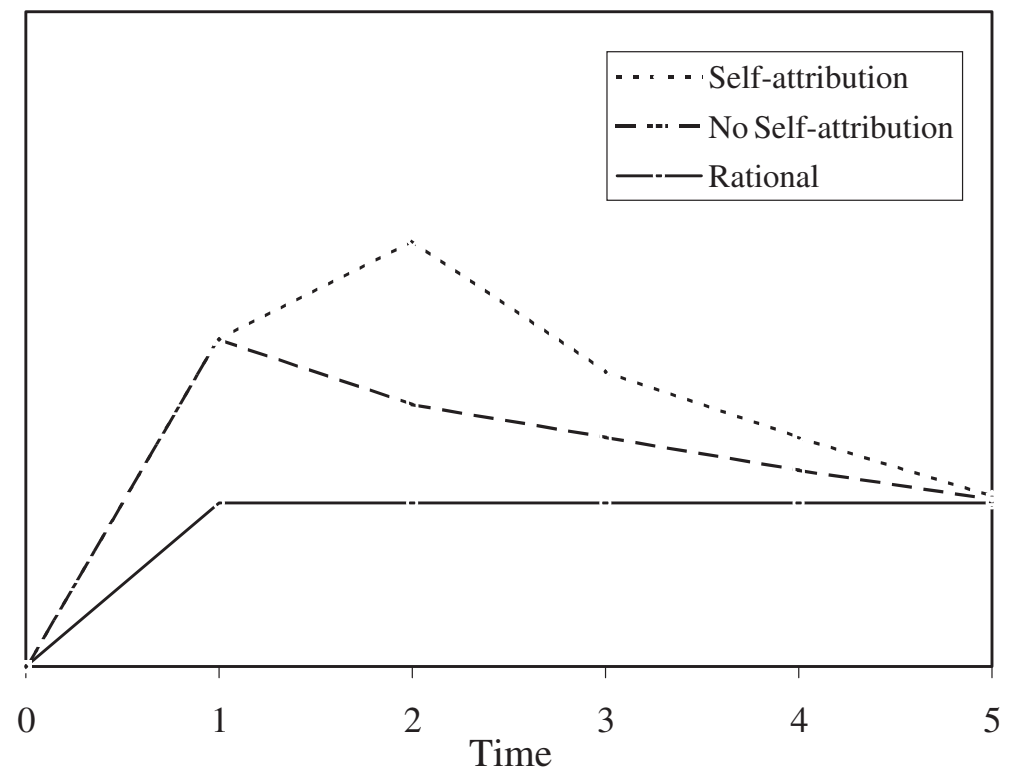

Fig. 1. Hypothesized price patterns with investors exhibiting overconfidence and self-attribution biases in the IPO aftermarket. Investors receive a private signal at time 0 to the effect that the IPO is underpriced; overconfidence on their part causes the Day 1 price to overshoot the rational level. Public signals at time 1 reinforce the private assessment and self-attribution bias causes the price to rise even further at time 2 . Reversal sets in beyond time 2. This graph is adapted from Fig. 1, p. 1847 of DHS. The discrete time points are purely illustrative. For instance, actual time between time 0 and time 1 may be just one day. The distance between time 1 and time 2 could be several weeks and so on.

initial positive momentum). This theoretical framework allows us to formulate the following research hypotheses:

H1. If investor biases along the lines suggested by DHS exist in the post-IPO environment, we should observe aftermarket patterns that exhibit short-run positive momentum and gradual reversal in cumulative market-adjusted returns (CMARs).

H2. IPO aftermarket patterns will be primarily a function of publicly observable momentum variables rather than firm-specific fundamental variables.

\subsection{Sample description}

In executing the study, we assume the perspective of an investor who has no preferential allotment in the IPO and has access only to freely available information. Our self-imposed constraint is that the investor should be able to implement her strategy without access to large research departments or subscriptions to expensive databases. Accordingly, our primary sample of high-tech firms was drawn from ipo.com, which lists the universe of US IPOs with dates, offer prices etc. broken down in a number of categories. We chose all IPOs from January 1, 1998 through October 
30, 1999 in the following sectors: biotechnology, computer hardware, computer software, electronics, Internet services, Internet software and telecommunications. This resulted in a sample of 301 high-tech IPO firms. ${ }^{8}$

The Day 1 open price and daily open prices for each firm in the sample and the corresponding NASDAQ index level are downloaded for 125 trading days $(\approx 6$ months) beyond the IPO date from yahoo finance and edreyfus.com. ${ }^{9}$ We decided on a 6 month aftermarket window for a number of reasons. The study is predicated on previous work documenting initial underpricing and long-run underperformance (or at least the lack of superior long-run performance) of IPO firms. The hypothesized price-value divergence of interest relates to the IPO event and future events such as seasoned offerings or mergers would confound the findings - hence the study period cannot be too long. On the other hand, the period has to be long enough for the anomaly to play out and a meaningful timing strategy implemented from a practitioner viewpoint. Also, the lockup period after which founders can sell their shares generally expires after 6 months. This may introduce a source of uncertainty in the post 6-month aftermarket that we wanted to avoid. Finally, there was a structural market correction in the technology sector in mid 2000. Given that our high-tech IPO sample runs through October 1999, we felt it was important to avoid any complicating biases arising from the market correction. All these factors taken together convinced us that a 6-month aftermarket window was the appropriate choice.

\subsection{Description of variables}

To study aftermarket patterns, we decided to adopt a framework that involves setting up a hierarchy of thresholds of post-IPO market-adjusted returns - loosely in the spirit of investor determined price targets. Accordingly, the dependent variable is constructed on the basis of an event, which is defined when the CMAR for a firm crosses a given threshold.

Let $P_{i 1}$ represent the Day 1 open price of the $i$ th firm and let $P_{m 1}$ be the corresponding level of the market (Nasdaq) index. Similarly, $P_{i t}$ and $P_{m t}$ represent the open price at time $t$ of the $i$ th firm and the market respectively. The CMAR of the firm at time $t$ is calculated as

$$
\mathrm{CMAR}_{i t}=\frac{P_{i t} / P_{i 1}}{P_{m t} / P_{m 1}}-1
$$

The time in question does not refer to calendar time, but to the time from the IPO date. We use $25 \%, 50 \%$, and $100 \%$ as thresholds for the OLR and SPH models. For instance, an event occurs when the $\mathrm{CMAR}_{i t}$ exceeds $50 \%$. The following categories are useful in explaining the construction of the dependent variable for the OLR and SPH models. Each category represents the best possible return in the 6-month period

\footnotetext{
${ }^{8}$ The original sample was $316 ; 15$ firms are dropped due to incomplete information on one or more explanatory variables.

${ }^{9}$ Price data were cross-checked for validity from alternate sources.
} 
beyond the IPO date. For instance, for Category 4, a return greater than $100 \%(>1)$ is not possible.

\begin{tabular}{ll}
\hline Categories & Description \\
\hline Category 1 & $\mathrm{CMAR}_{i t}$ is in the $\leqslant 0$ range \\
Category 2 & $\mathrm{CMAR}_{i t}$ is in the $(0,0.25]$ range \\
Category 3 & $\mathrm{CMAR}_{i t}$ is in the $(0.25,0.50]$ range \\
Category 4 & $\mathrm{CMAR}_{i t}$ is in the $(0.50,1]$ range \\
Category 5 & $\mathrm{CMAR}_{i t}$ is in the $>1$ range \\
\hline
\end{tabular}

It may appear to the reader that the manner in which we construct our thresholds that define the ordered categories or even the number of categories is somewhat ad hoc. This is quite true but far from being a shortcoming, this is actually an advantage in the context of our application. It allows the individual investor to set her own bar in terms of CMAR expectation while the model itself is flexible enough to accommodate (within reason) any number of categories.

The crucial issues that we address in this paper are as follows: What is the probability that an average firm's market adjusted returns will cross a given threshold? How does this probability change over time in the 6-month IPO aftermarket? (see $\mathrm{H} 1$ above). Does this probability depend on fundamental or momentum variables? (see $\mathrm{H} 2$ above). It is worth noting that while we draw upon the DHS framework to formulate our research questions, the theory itself seeks to provide a general explanation of market under- and overreactions and does not provide direction on the choice of proxy variables for particular applications. Accordingly, potential explanatory variables, $X$, are selected with guidance from the empirical IPO literature and researcher intuition. The data sources used are ipo.com, FISonline, Hoovers.com, and Carter et al. (1998). The variables and our rationale for their selection are described below:

\begin{tabular}{ll}
\hline Variable & Expected sign \\
\hline Percentage price change: Initial underpricing (or overpricing & Negative \\
variable) that measures the change from the offer price to & \\
the open price. If the IPO is severely underpriced, we & \\
expect aftermarket momentum to be subdued & \\
Adjusted return in week 1: Momentum (purely technical) & Positive \\
variable representing the average market-adjusted return & \\
in the first week of trading. It is a proxy for the favorable & \\
public signal that might induce the DHS self-attribution bias & \\
Market return in week 1: Momentum (purely technical) & Positive \\
variable representing the average market return in the & \\
first week of trading. It represents a second-order proxy & \\
for the self-attribution bias &
\end{tabular}




\begin{tabular}{|c|c|}
\hline Variable & Expected sign \\
\hline $\begin{array}{l}\text { Net income/revenue: Net income divided by revenue in the } \\
\text { pre-IPO year. A fundamental variable that is a proxy for } \\
\text { firm quality }\end{array}$ & $\begin{array}{l}\text { Positive or } \\
\text { no effect }\end{array}$ \\
\hline $\begin{array}{l}\text { Underwriter reputation: Lead underwriter's reputation } \\
\text { based on the Carter-Manaster measure. It has been used in } \\
\text { previous work to explain underpricing. If accurate pricing } \\
\text { goes together with underwriter reputation, we expect } \\
\text { post-IPO biases to be reduced }\end{array}$ & Negative \\
\hline $\begin{array}{l}\text { Offer size: Offer price multiplied by the number of shares } \\
\text { sold in the IPO. We use the log value of the offer size. } \\
\text { The variable is a proxy for size }\end{array}$ & Negative \\
\hline $\begin{array}{l}\text { Green shoe dummy: Dummy variable for a green shoe } \\
\text { provision in the IPO contract. This provision gives the } \\
\text { underwriter the option to purchase additional shares at } \\
\text { the offer price to cover over allotments. Presence of the } \\
\text { provision indirectly increases underwriter compensation }\end{array}$ & No prior \\
\hline $\begin{array}{l}\text { Computer software and hardware dummy: Dummy variable } \\
\text { takes value } 1 \text { if the firm belongs either to the computer } \\
\text { hardware or software sectors }\end{array}$ & No prior \\
\hline $\begin{array}{l}\text { Internet services and software dummy: Dummy variable } \\
\text { takes value } 1 \text { if the firm belongs either to the Internet } \\
\text { services or Internet software sectors. A sense that within } \\
\text { the high-tech sector, the business models of Internet firms } \\
\text { (e-commerce or e-commerce enablers) are more uncertain }\end{array}$ & Positive \\
\hline $\begin{array}{l}\text { Telecommunications dummy: Dummy variable takes } \\
\text { value } 1 \text { if the firm belongs to the telecommunications sector }\end{array}$ & No prior \\
\hline $\begin{array}{l}\text { Age before the IPO: Represents the number of years from } \\
\text { the date the firm was incorporated to the IPO date. } \\
\text { A fundamental variable that is a weak proxy for firm quality }\end{array}$ & $\begin{array}{l}\text { Positive or } \\
\text { no effect }\end{array}$ \\
\hline
\end{tabular}

Table 1 provides a comparison between the distribution of firms across the five categories if the investor always cashes out at the point when the threshold is reached versus the distribution that results if a simple 6-month 'buy and hold' (BH) strategy is adopted. It should be noted that 'selling at the threshold' (ST) is based on perfect hindsight and that $\mathrm{BH}$ is a naïve strategy that involves buying every IPO stock at the Day 1 open price and selling it after six months. Nonetheless, the contrast is striking. With the ST strategy, 112 firms $(37.2 \%$ of the total) end up in category 5 (CMAR 
Table 1

Distribution of IPO firms across categories based on BH and ST strategies

\begin{tabular}{llc}
\hline Categories & Number of firms & \\
\cline { 2 - 3 } & BH strategy & ST strategy \\
\hline C1 $(\leqslant 0)$ & 170 & 48 \\
C2 $(0,0.25]$ & 21 & 50 \\
C3 $(0.25,0.50]$ & 27 & 37 \\
C4 $(0.50,1.0]$ & 29 & 54 \\
C5 $(>1)$ & 54 & 112 \\
\hline
\end{tabular}

The BH strategy involves buying at the Day 1 open price and selling exactly six months later.

The ST strategy assumes perfect hindsight and requires buying at the Day 1 open price and selling at the point the threshold (not necessarily price peak) is reached.

For both BH and ST strategies, observations in a category are based on the best possible returns. For instance, for an observation in C4, greater than $100 \%(>1)$ return in the 6-month period beyond the IPO date is not possible.

exceeding $100 \%)$ whereas only 54 firms $(17.9 \%$ of the total) achieve the same result under $\mathrm{BH}$. Also, the numbers of firms ending up in category 1 (negative CMAR) are $48(15.9 \%$ of total) for the ST versus $170(56.5 \%$ of total) for the $\mathrm{BH}$ strategy.

The advantage of ST over BH is even more compelling when the mean CMARs are examined. In Table 2, we present the CMARs associated with holding on to the position for 6-months instead of cashing out at the point when the threshold is reached. For instance in category $\mathrm{C} 4$, the ST strategy would garner mean CMARs between $50 \%$ and $100 \%$ by construction $(61.39 \%$ to be exact). However, if the long position in the 54 firms that make it to $\mathrm{C} 4$ under the ST strategy were maintained for 6-months, the mean CMAR shrinks to $-4.70 \%$. For $\mathrm{C} 3$, the swing is from $31.06 \%$ to $-26.17 \%$.

Table 2

Mean market-adjusted returns based on ST and after 6-months in the various categories defined by the ST strategy

\begin{tabular}{llll}
\hline Categories & $\begin{array}{l}\text { Number of firms } \\
\text { (ST strategy) }\end{array}$ & $\begin{array}{l}\text { Mean returns at ST } \\
(\%)\end{array}$ & $\begin{array}{l}\text { Mean 6-month returns } \\
(\%)\end{array}$ \\
\hline C1 $(\leqslant 0)$ & 48 & -57.40 & -57.40 \\
C2 $(0,0.25]$ & 50 & 5.88 & -44.79 \\
C3 $(0.25,0.50]$ & 37 & 31.06 & -26.17 \\
C4 $(0.50,1.0]$ & 54 & 61.39 & -4.70 \\
C5 $(>1)$ & 112 & 118.15 & 133.67 \\
\hline
\end{tabular}

The mean 6-month returns represent the returns to investors who hold on to the long position for 6months instead of ST.

In category $\mathrm{C} 4$, the ST strategy would garner a mean market-adjusted return of between 50 and $100 \%$ by construction $(61.39 \%$ to be exact). However, if the long position in the 54 firms that make it to $\mathrm{C} 4$ under the ST strategy were maintained for 6-months, the mean market-adjusted return shrinks to $-4.70 \%$. 
Table 3

Average factor values across the categories based on the ST strategy

\begin{tabular}{|c|c|c|c|c|c|c|}
\hline Variables & $\begin{array}{l}\mathrm{C} 1 \\
(\leqslant 0)\end{array}$ & $\begin{array}{l}\mathrm{C} 2 \\
(0,0.25]\end{array}$ & $\begin{array}{l}\mathrm{C} 3 \\
(0.25,0.50]\end{array}$ & $\begin{array}{l}\mathrm{C} 4 \\
(0.50,1.0]\end{array}$ & $\begin{array}{l}\mathrm{C} 5 \\
(>1)\end{array}$ & All \\
\hline Percentage price change & 97.91 & 62.06 & 51.48 & 57.81 & 51.87 & 61.92 \\
\hline Adjusted return in week 1 & -21.17 & -4.08 & 1.14 & 4.29 & 15.51 & 2.63 \\
\hline Market return in week 1 & -0.47 & -0.16 & -0.29 & 0.56 & 0.51 & 0.15 \\
\hline Net income/revenue & -1.02 & -1.95 & -2.17 & -1.39 & -2.05 & -1.77 \\
\hline Underwriter reputation & 0.75 & 0.64 & 0.89 & 0.76 & 0.88 & 0.80 \\
\hline Offer size & 17.75 & 17.94 & 17.98 & 18.05 & 17.96 & 17.94 \\
\hline Green shoe dummy & 0.44 & 0.50 & 0.68 & 0.65 & 0.60 & 0.57 \\
\hline $\begin{array}{l}\text { Computer software and } \\
\text { hardware dummy }\end{array}$ & 0.15 & 0.18 & 0.24 & 0.13 & 0.16 & 0.17 \\
\hline $\begin{array}{l}\text { Internet services and } \\
\text { software dummy }\end{array}$ & 0.73 & 0.50 & 0.43 & 0.57 & 0.67 & 0.60 \\
\hline $\begin{array}{l}\text { Telecommunications } \\
\text { dummy }\end{array}$ & 0.10 & 0.20 & 0.27 & 0.24 & 0.14 & 0.18 \\
\hline $\begin{array}{l}\text { Age before the IPO } \\
\text { (in years) }\end{array}$ & 4.64 & 6.07 & 6.17 & 5.71 & 4.82 & 5.33 \\
\hline Number of observations & 48 & 50 & 37 & 54 & 112 & 301 \\
\hline
\end{tabular}

Table 3 contains descriptive statistics (mean values of explanatory variables) across the categories defined by the ST strategy. It is interesting to note that the 48 firms that end up in category C1 (strictly negative CMARs beyond the Day 1 open price) were underpriced by $98 \%$ on average compared to $62 \%$ for the total sample. ${ }^{10}$

Tables 1 and 2 indicate that for all firms in categories $\mathrm{C} 2$ and above $(253 \mathrm{firms}$ representing $84 \%$ of the sample), the aftermarket CMAR exhibits momentum and many of the firms suffer a reversal within a 6-month period. The explanatory variables defined above may capture aftermarket momentum effects but not reversal a phenomenon that is central to our inquiry.

Therefore, we construct two additional (artificial) variables for the OLR model. The first such variable (time) represents the time in weeks from the IPO date to the optimal sell date (defined as the date the threshold is reached, not necessarily the peak stock price) and the second variable is simply time squared to capture the implicit non-linearity (or reversal). We fully realize that these two variables involve ex post look back and cannot be used in a pure predictive model. However, as discussed in the following OLR results section, we will show that it is possible to simulate the effect of the time variables to estimate the probabilities of ending up in the various categories by evaluating the other non-look back variables.

\footnotetext{
${ }^{10}$ Loughran and Ritter (2002b, Table 2) report average first-day returns to Technology and Internetrelated IPOs of $81.1 \%$ in the $1999-2000$ period and $22.7 \%$ in the $1990-98$ period. Our sample underpricing average of $61.9 \%$ is clearly representative for the $1998-99$ period. Also, see Arosio et al. (2000).
} 


\section{Ordered logit regression model and results}

\subsection{OLR methodology}

We execute an OLR in which the dependent variable is based on the CMAR ${ }_{i t}$. OLR models are useful when the dependent variable represents an outcome of a decision between a finite set of alternatives that are naturally ordered (see Greene, 2000). Examples include opinion surveys (strongly agree, agree, disagree and strongly disagree), insurance coverage (full, partial, none), bond ratings, etc. In this application, a firm's aftermarket IPO performance falls into one of the five ordered categories defined above. The OLR model seeks to explain the influence of variables on the probability of the firm falling into these categories.

Consider $Y_{1}, Y_{2}, Y_{3}, Y_{4}, Y_{5}$ where $Y_{j}$, representing category $j$ above, equals 1 if $\mathrm{CMAR}_{i t}$ exceeds some threshold value; 0 otherwise. For instance, for Category 5, $Y_{5}=1$ if $\mathrm{CMAR}_{i t}>1.0$ and $Y_{1}=Y_{2}=Y_{3}=Y_{4}=0$. Similarly $Y_{4}=1$ if $\mathrm{CMAR}_{i t}>0.5$, but never exceeds 1 , and $Y_{1}=Y_{2}=Y_{3}=Y_{5}=0$. The above categories are defined when the threshold is first reached. At this point, the time variable defined as the number of weeks after the IPO date is also recorded. For instance if the firm's CMAR becomes $100 \%$ in 20 trading days, $Y_{5}$ equals 1 and the time variable takes on value 4 . For the worst category $\left(Y_{1}=1\right)$ the adjusted return is never positive and the time variable is set equal to zero.

In the estimation process, consider an underlying performance variable $(Z)$ that is continuous but only the discrete response is observed. Also, consider the following grid that slots firms in to the various categories:

\begin{tabular}{lllllllllll}
$Y_{1}=1$ & $\mid$ & $Y_{2}=1$ & $\mid$ & $Y_{3}=1$ & $\mid$ & $Y_{4}=1$ & $\mid$ & $Y_{5}=1$ & $\mid$ & \\
\hline & $\gamma_{0}$ & & $\gamma_{1}$ & & $\gamma_{2}$ & & $\gamma_{3}$ & $\gamma_{4}$ & $Z$
\end{tabular}

$P\left(Y_{1}=1\right)=P\left(Z<\gamma_{0}\right), P\left(Y_{2}=1\right)=P\left(\gamma_{0} \leqslant Z<\gamma_{1}\right)$, etc. For an ordered logit model,

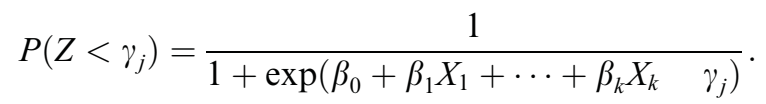

The coefficient $\beta_{j}$ measures the influence of the explanatory variable $X_{j}$ on the probability of falling into a particular category. The $\gamma$ 's are the unknown parameters to be estimated along with the $\beta$ 's. These probabilities are used to specify the following log-likelihood function that is maximized to obtain the parameter estimates:

$$
£=\sum_{i=1}^{N}\left[\sum_{j=1}^{5}\left(Y_{j}=1\right) \ln P\left(Y_{j}=1\right)\right] .
$$

The results of the OLR are reported in Table 4. It should be noted that the interpretation of the coefficients in an OLR is not straightforward. However, in our application, a significantly positive coefficient implies that the variable positively influences the probability of a good outcome from the investor's point of view, 
Table 4

OLR model estimates

\begin{tabular}{|c|c|}
\hline Parameters & Estimates ( $t$-statistics) \\
\hline Constant & $\begin{array}{c}3.185 \\
(1.113)\end{array}$ \\
\hline Time & $\begin{array}{r}1.040^{*} \\
(11.541)\end{array}$ \\
\hline Time-squared & $\begin{array}{c}-0.036^{*} \\
(-9.853)\end{array}$ \\
\hline Percentage price change & $\begin{array}{c}-0.002 \\
(-1.349)\end{array}$ \\
\hline Market-adjusted return in week 1 & $\begin{array}{r}0.106^{*} \\
(10.785)\end{array}$ \\
\hline Market return in week 1 & $\begin{array}{c}0.167^{*} \\
(3.060)\end{array}$ \\
\hline Net income/revenue & $\begin{array}{c}0.028 \\
(0.674)\end{array}$ \\
\hline Underwriter reputation & $\begin{array}{c}0.662^{* *} \\
(1.896)\end{array}$ \\
\hline Offer size & $\begin{array}{c}-0.200 \\
(-1.200)\end{array}$ \\
\hline Green shoe dummy & $\begin{array}{c}0.551^{*} \\
(2.013)\end{array}$ \\
\hline Computer software and hardware dummy & $\begin{array}{c}0.405 \\
(0.605)\end{array}$ \\
\hline Internet services and software dummy & $\begin{array}{l}1.421^{*} \\
(2.140)\end{array}$ \\
\hline Telecommunications dummy & $\begin{array}{c}0.012 \\
(0.017)\end{array}$ \\
\hline Age before the IPO (in years) & $\begin{array}{c}0.005 \\
(0.191)\end{array}$ \\
\hline
\end{tabular}

${ }^{*}$ and ${ }^{* *}$ denote significance at $5 \%$ and $10 \%$ level respectively.

The dependent variable is captured in terms of the dummy variables $Y_{1}, Y_{2}, Y_{3}, Y_{4}, Y_{5}$ where $Y_{j}=1$ if cumulative market adjusted exceeds a given threshold value; 0 otherwise.

i.e., the probability that the CMAR will end up in category 4 (50-100\% range) or 5 $(>100 \%$ range) and vice versa.

\subsection{Discussion of OLR results}

The hypothesized momentum and reversal effects are strongly confirmed. Both momentum (biased self-attribution) proxy variables: the IPO firm's average market-adjusted return and the average market (Nasdaq) return in the first week following the IPO have positive and highly significant coefficients. Further, the time and timesquared variables are also strongly significant with positive and negative coefficients respectively. In the context of the DHS price formation theory, overconfident investors cause stock prices to overreact initially (the jump from offer to market open price), biased self-attribution potentially induced by upward movement in the IPO firm's stock price and the market generally in the week following the IPO causes a 
further overreaction (the continuation of positive returns implied by our momentum variables) and the eventual reversal sets in as price-value convergence is induced with the continual arrival of public information (inferred from our time-squared variable and the patterns documented in Tables 1 and 2). From the speculative investor's point of view, it pays to hold the stock for a while in the initial period after the IPO because the probability of landing in the higher categories is improving but as more time passes, this probability wanes.

Also, as hypothesized, fundamental variables do not appear to influence the IPO aftermarket. For instance, the profitability (or lack thereof) of the firm measured as net incomelrevenue in the pre-IPO year has no effect. Similarly, the number of years that the firm has been in business prior to the IPO (age before the IPO) does not seem to matter. These are classic 'old-economy' variables that supposedly enable formation of expectations about future cash flows and/or risk. Also, the extent of initial underpricing (measured as the percentage price change from the IPO offer price to the Day 1 open market price) does not play a role in the aftermarket. Perhaps the IPO offer price in conjunction with the first available market price (Day 1 open) subsumes other fundamental information (such as profitability and firm age) contained in the prospectus and therefore these variables ought not to affect aftermarket prices in an efficient markets framework. However, a less benign explanation is that momentum investors, for whom fundamental variables do not matter, dominate the immediate aftermarket.

Some variables related to the IPO contract do seem to matter. Underwriter reputation ${ }^{11}$ (contrary to our prior) and the presence of a green shoe provision are associated with positive aftermarket returns while the offer size appears to have no effect. Within the high-tech umbrella, designation as an Internet firm is associated with positive aftermarket returns; other industry dummy variables are insignificant.

It is worth exploring the underwriter reputation variable a little further. We had expected that it would be negatively related to aftermarket returns - the logic being that highly ranked underwriters would set a more accurate offer price and a perception of fairer pricing would dampen aftermarket biases. In fact earlier studies do suggest that initial underpricing (or the amount of money left on the table by the IPO firm) is inversely related to underwriter reputation (see Carter et al., 1998). But this relationship seems to have flipped (turned positive) in the 1990s and especially in the 1999-2000 period (see Loughran and Ritter, 2002b, Table 7). Why should this be the case? Loughran and Ritter (2002b) propose two hypotheses: (a) "the analyst coverage hypothesis" - the idea here is that the issuing firm places more importance on snagging a lead underwriter with a highly ranked analyst to cover the firm and downplays underpricing; and (b) "the corruption hypothesis" - this refers to side payments made by the underwriter to founders and senior executives of the issuing firm usually in the form of allocation of shares in other hot IPOs.

\footnotetext{
${ }^{11}$ The original analysis was done using the Carter-Manaster reputation rankings. We found that almost all the lead underwriters in our sample were at the high end $(>7)$. We ultimately substituted the Carter-Manaster number with a dummy variable which takes value 1 if the underwriter ranking was greater than 7; 0 otherwise.
} 
We think that these hypotheses are compatible with the DHS theory and our own findings. The source of investor overconfidence and self-attribution biases particularly in technology stocks could well have been less-than-objective sell-side analyst recommendations serving as public signals. Numerous recent stories in the business press have reported on the conflicts of interests and the breaching of Chinese walls between the brokerage-advice and investment banking divisions at major Wall Street firms. ${ }^{12}$ If anything, underwriter incentives are served firstly through underpricing but also by propping up the price in the aftermarket so that their preferred clients can bail out in an orderly manner.

We do not wish to convey the impression that the DHS theory is the only explanation for the momentum/reversal patterns that we document in the high-tech IPO aftermarket. It is however a reasonably convincing theoretical framework within which it is possible to formulate and empirically test hypotheses, as we have attempted to do in this study. There are a number of other theories that also attempt to explain generally the less-than-efficient market reaction to various types of events. For instance Hong and Stein (1999) postulate two classes of investors: momentum investors who chase price trends and ignore fundamental information causing price overreactions in the process; and news watchers who use fundamental information but ignore prices and are thereby the source for underreactions. It is possible that the IPO aftermarket patterns that we detect could be explained in such a framework. ${ }^{13}$ The DHS theory does have the advantage of being grounded in psychological biases that have been verified in experimental settings. In our opinion, it would be difficult if not impossible to design an empirical study using capital market data to directly test any of the behavioral finance theories.

Our OLR model cannot be used in a traditional predictive sense because the time variable is constructed using ex post look back. However, it is possible to simulate the probabilities of various outcomes for different values of the time variable. In Fig. 2, we report the results of the simulation analysis that generates predicted proportions for categories 4 and 5 combined (market-adjusted returns in excess of 50\%) with respect to time expressed in number of weeks, and the other explanatory variables at their actual ex ante values for each firm. The simulated proportions (or probabilities) are averaged across our sample of 301 high-tech IPO firms.

The probability of earning market-adjusted returns of at least $50 \%$ increases over time, peaks at around 14 weeks from the IPO date and wanes thereafter. It is important to note that the probabilities reported in Fig. 2 are conditional on the time variable taking on a positive value. As indicated earlier, the value of the time variable is determined when the ordered threshold is crossed but takes on a value of zero if the firm never does cross any positive market-adjusted return threshold, i.e., ends up being a category 1 firm. Therefore, in determining the cash-out point with ex-ante simulation, the probability estimates that the model generates are overstated. The

\footnotetext{
${ }^{12}$ See for instance Morgenson (2002).

${ }^{13}$ Or indeed in other settings as in Shiller (1984), Barberis et al. (1998) or Delong et al. (1990).
} 


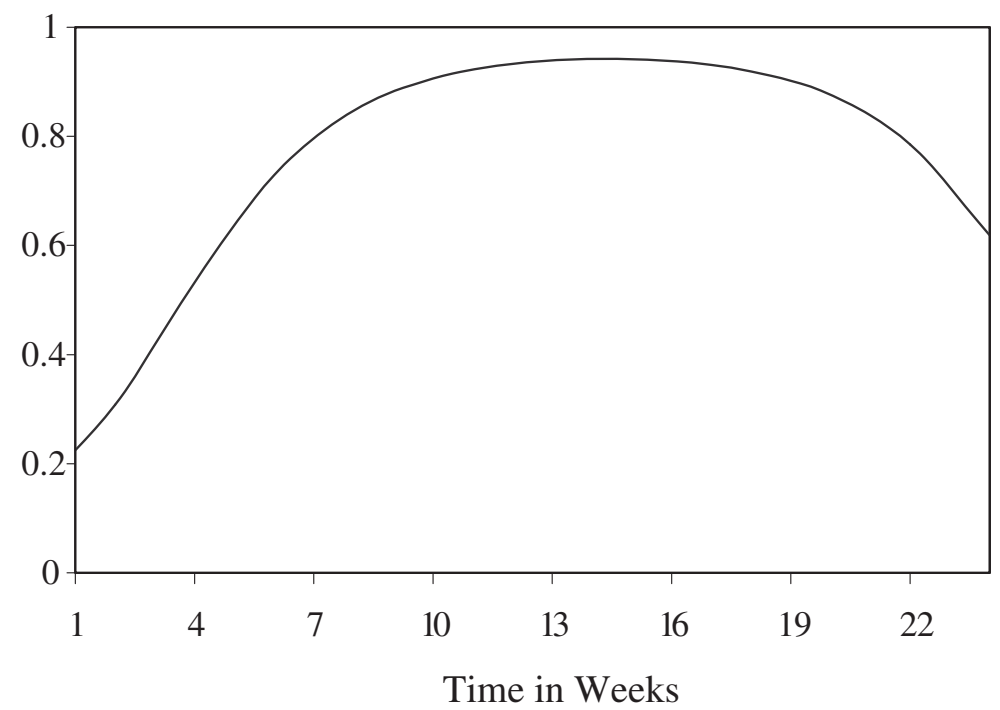

Fig. 2. Predicted probability of $50 \%$ or higher returns from an ordered logit model. Results of a simulation exercise with respect to the time variable where all other variables are evaluated based on their ex-ante actual values. Proportions for Categories 4 and 5 simulated for each firm and then averaged across the sample. The above simulated results are conditional on positive adjusted returns since we have set time $=0$ for negative returns. These results are broadly comparable with raw data. The raw mean of the time variable corresponding to each category is given by 0 weeks for $\mathrm{C} 1,3.8$ weeks for $\mathrm{C} 2,8.1$ weeks for $\mathrm{C} 3,12.7$ weeks for C4, and 9.6 weeks for C5.

pattern of the probability numbers (but not the numbers themselves) is the salient information to be drawn from Fig. 2.

\section{Split-population hazard model and results}

\subsection{SPH methodology}

As mentioned earlier, the time variable in our OLR model is constructed artificially with the benefit of ex post look back. We use an alternative statistical technique to endogenize the influence of 'time' and also to check how well the aftermarket patterns hold up. Hazard rate models are often employed to explain the duration of an event of interest (see Greene, 2000). In this paper, we define an event when the CMAR crosses a certain threshold. A hazard rate model is used to capture the effect of various factors on the instantaneous probability that a given threshold is crossed. Further, it also enables us to capture the timing issue by analyzing how this probability changes over time.

Standard hazard rate models are implicitly based on the assumption of certain exit implying that the event will eventually be defined. However, since an IPO invest- 
ment may not always lead to the market-adjusted threshold returns of $25 \%, 50 \%$, or $100 \%$, we use a SPH model (see Bandopadhyaya and Jaggia (2001) for details) that takes into account the possibility that for some firms the exit may never occur. We run three separate SPH models (for thresholds of $25 \%, 50 \%$, and $100 \%$ ) where the hazard parameters are estimated along with a split parameter that represents the probability of eventual success.

We observe two kinds of firms: (a) firms that reach the threshold (complete observations) and (b) firms that do not reach the threshold (censored observations). Let a censoring variable $C$ equal 1 for complete and 0 for censored observations. In standard hazard rate models the contribution of complete and censored observations, conditional on the $X$ 's, at time $t$ are $P(T=t)$ and $P\left(T>t_{i}\right)$ respectively. In an SPH model, the contributions are $\delta P\left(T=t_{i}\right)$ and $1 \delta+\delta P\left(T>t_{i}\right)$ respectively where $\delta$ represents the probability of eventual success. We use a log-logistic hazard function given by

$$
h(t ; X)=\exp (X \beta) \alpha t^{\alpha}{ }^{1}\left(1+\exp \left(\beta^{\prime} X\right) t^{\alpha}\right)^{1},
$$

where $\beta^{\prime} X=\beta_{0}+\beta_{1} X_{1}+\beta_{2} X_{2}+\cdots+\beta_{k} X_{k}$, and $\alpha$ is the shape parameter of the hazard that determines the point after which the hazard declines. It is useful to note that if a variable has a positive impact on the hazard, then it has a negative impact on the time it takes to reach a threshold. The log-likelihood function for an SPH is

$$
£=\sum_{i=1}^{N} C\left[\ln \delta+\ln \alpha+w \quad 2 \ln \left(1+\mathrm{e}^{w}\right)\right]+\left(\begin{array}{ll}
1 & C
\end{array}\right)\left[\ln \left(1 \quad \delta+\delta\left(1+\mathrm{e}^{w}\right)\right)^{1}\right],
$$

where $w=\beta^{\prime} X+\alpha \ln t$ and $C$ is a censoring variable. The split parameter $\delta$ allows the probability of eventual success to be different from one and if the estimated $\delta$ is not significantly different from 1 , the split model converges to a standard hazard model.

\subsection{SPH model results and discussion}

The results from the SPH regressions for market-adjusted return thresholds of $25 \%, 50 \%$, and $100 \%$ respectively are presented in Table 5 . We observe that they are generally consistent with those obtained from the OLR procedure. The momentum variables - the firm's average market-adjusted return and the average market (Nasdaq) return in the first week following the IPO - are significant and positively influence the hazard (instantaneous probability of reaching the specified threshold given that it has not been achieved up to the previous instant) for all three thresholds. Also, the shape parameter $\alpha$ is strongly significant and greater than one for all thresholds. Recall that this parameter in the hazard-modeling context indicates how 'elapsed time' plays a role in explaining the hazard over time. In our application, given the log-logistic specification, the $\alpha$ estimate indicates that the hazard increases initially, reaches a peak and then begins to wane. The hypothesized momentumreversal aftermarket patterns are unequivocally confirmed by the SPH modeling approach. 
Table 5

Estimates of the split-population log-logistic hazard models for the $25 \%, 50 \%$, and $100 \%$ thresholds

\begin{tabular}{lccc}
\hline Parameters & Estimates $(t$-value) & & \\
\cline { 2 - 4 } & $25^{\circ}$ & $50^{\circ}$ & $100^{\%}$ \\
\hline Constant & -4.198 & -1.321 & -1.220 \\
& $(-1.312)$ & $(-0.398)$ & $(-0.311)$ \\
Percentage price change & $-0.004^{*}$ & -0.002 & $-0.004^{* *}$ \\
& $(-2.146)$ & $(-1.114)$ & $(-1.799)$ \\
Adjusted return in week 1 & $0.072^{*}$ & $0.070^{*}$ & $0.071^{*}$ \\
Market return in week 1 & $(10.241)$ & $(10.020)$ & $(8.934)$ \\
Net income/revenue & $0.103^{*}$ & $0.165^{*}$ & $0.130^{*}$ \\
& $(1.991)$ & $(3.144)$ & $(2.041)$ \\
Underwriter reputation & -0.027 & $0.079^{* *}$ & -0.039 \\
Offer size & $(-0.665)$ & $(1.880)$ & $(-0.790)$ \\
Green shoe dummy & $0.976^{*}$ & 0.527 & $1.531^{*}$ \\
Computer software and & $(2.493)$ & $(1.477)$ & $(3.290)$ \\
hardware dummy & -0.001 & -0.235 & $-0.436^{* *}$ \\
Internet services and soft- & $(-0.005)$ & $(-1.212)$ & $(-1.906)$ \\
ware dummy & $1.247^{*}$ & $0.604^{*}$ & 0.412 \\
Telecommunications dummy & $(4.475)$ & $(2.152)$ & $(1.255)$ \\
Age before the IPO (in years) & 0.853 & 0.878 & $1.530^{* *}$ \\
$\alpha$ (shape parameter) & $(1.211)$ & $(1.260)$ & $(1.729)$ \\
$\delta$ (split parameter) & 1.128 & $1.909^{*}$ & $2.650^{*}$ \\
& $(1.632)$ & $(2.867)$ & $(2.993)$ \\
& 0.367 & 0.845 & 1.007 \\
& $(0.513)$ & $(1.217)$ & $(1.105)$ \\
and & -0.017 & 0.001 & 0.015 \\
& $(-0.587)$ & $(0.058)$ & $(0.398)$ \\
& $1.453^{*}$ & $1.382^{*}$ & $1.822^{*}$ \\
& $(3.721)$ & $(2.701)$ & $(4.431)$ \\
& $0.826^{*}$ & 0.881 & $0.708^{*}$ \\
& $(-4.004)$ & $(-1.483)$ & $(-4.288)$ \\
\hline
\end{tabular}

${ }^{*}$ and ${ }^{* *}$ denote significance at $5 \%$ and $10 \%$ level respectively.

For $\alpha$ and $\delta$, the $t$-statistic is evaluated at 1 .

The regression coefficients capture the influence of the factors on the hazard. The shape parameter $\alpha$ determines the point after which the hazard declines. The split parameter $\delta$ represents the probability of eventual success.

The fundamental variables, net incomelrevenue and age before the IPO, are generally insignificant as we found under OLR; the one exception is that net incomelrevenue is weakly significant for the $50 \%$ threshold. The influence of the other explanatory variables is broadly in line with the OLR findings. The underwriter reputation variable is positively associated with the hazard in all cases and highly significant for the $25 \%$ and 100\% thresholds. Similarly, the green shoe and the Internet industry dummy variable coefficients are positive as before but significant only in two out of three cases. One difference in the SPH findings is that the underpricing variable (percentage price change) has the hypothesized negative sign and is significant in two out three cases. This indicates that the higher the extent of initial underpricing the lower the probability of crossing the aftermarket threshold. In the OLR estimation, this coefficient was negative although insignificant. 


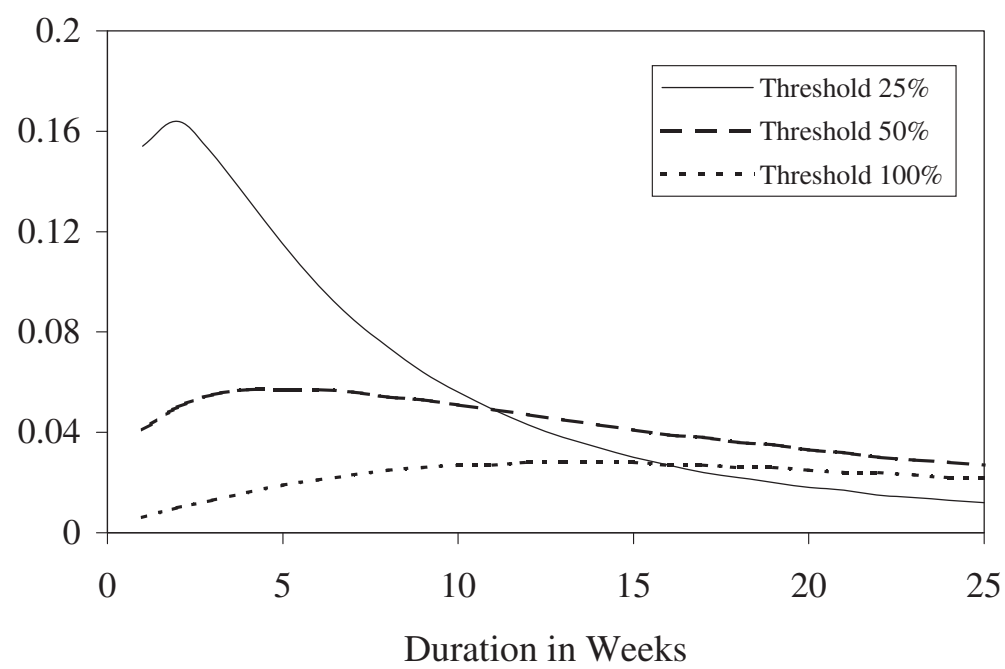

Fig. 3. Aggregate hazard of the split-population log-logistic models for the $25 \%, 50 \%$, and $100 \%$ thresholds. The aggregate hazard is calculated for the estimated SPH models with the factors evaluated at their mean value.

The lack of complete concordance between OLR and SPH is not really surprising given that they are non-nested statistical procedures involving maximum likelihood estimation. We are pleased to note that regardless of the procedure, our hypotheses regarding aftermarket patterns and the dominance of momentum over fundamental variables hold up very well.

SPH yields an additional insight, i.e., the probability that the threshold will be reached eventually though not necessarily within 6 months. This point estimate is captured by the split parameter $\delta$, which is strongly significant for the 25 $(\delta=0.826)$ and $100(\delta=0.708) \%$ thresholds. ${ }^{14}$

In Fig. 3, we plot the aggregate hazard against duration in weeks from the IPO date. We observe that the hazard ramps up in the initial weeks, reaches a peak and then declines. For the 50\% (100\%) threshold, the peak is reached at around 5 (13) weeks, which also represents the optimal cash-out points averaged across our sample. Recall from Fig. 2 that the OLR procedure indicated that the simulated probability of reaching a threshold of $50 \%$ or better (combined probabilities for the $\mathrm{C} 4$ and $\mathrm{C} 5$ categories) reached a maximum at 14 weeks. The broad aftermarket patterns of momentum and reversal are revealed under both modeling approaches.

\footnotetext{
${ }^{14}$ Our model displays a slight inconsistency with regard to the split parameter $\delta$. Ideally, we would like to see a declining estimate as the threshold increases. But the insignificant $\delta$ coefficient $(0.881)$ for the $50 \%$ threshold lies above that for the $25 \%$ threshold. We reran the model for a $75 \%$ threshold and reassuringly obtained an estimate of 0.72 , which is below the 0.826 probability for the $25 \%$ threshold and above the 0.708 probability for the $100 \%$ threshold.
} 
Note that the aggregate hazard function for the $25 \%$ threshold has a more pronounced inverted $U$ shape with the peak reached just 2 weeks after the IPO date and a fairly rapid fall-of thereafter. By contrast, the hazard functions for the $50 \%$ and $100 \%$ thresholds rise and fall more gently with the peaks reached at a lower point than the $25 \%$ threshold. This fits with the intuitive expectation that a lower threshold strategy can be executed relatively quickly with a higher probability of success. The required holding period increases with the threshold while the probability of actually reaching the threshold declines, as would be the case with any speculative investment strategy.

A recent paper by Aggarwal et al. (2002) presents an interesting model where managers strategically underprice IPOs to maximize wealth by selling shares at lockup expiration. In their model, initial underpricing generates momentum, which presumably lasts through the lockup expiration date. While our study does not explicitly control for the lockup expiration, we limit our aftermarket analysis to six months beyond the IPO date. And as discussed above, the momentum lasts for only a few weeks before the reversal sets in. Unless the lockup expiration is well below six months (which seems unlikely) for the firms in our sample, our results would appear to contradict the prediction of their model. On the other hand, managers would not care about market-adjusted returns but simply raw returns and we have not considered unconditional momentum-reversal patterns based on unadjusted aftermarket prices.

\section{Conclusion}

In this paper, we study the 6-month aftermarket in high-tech US IPOs launched in the late 1990s. We draw on the DHS theoretical framework of investor overconfidence and biased self-attribution to hypothesize short-run positive momentum and gradual reversal in post IPO returns. Both our methodological approaches (OLR and $\mathrm{SPH}$ ) confirm these patterns. We also find that momentum variables explain most of the aftermarket price behavior while fundamental indicators have weak influence at best.

At this stage, we are unsure if our results can be replicated with a broader sample and in a more benign investment climate than the late 1990s. Our sense is that while our narrowly drawn sample may exhibit somewhat more extreme characteristics, the long-standing IPO underpricing anomaly is likely to portend similar if more muted IPO aftermarket patterns. A number of regulatory changes have occurred in recent years. The effective repeal of Glass-Steagall has resulted in significant consolidation in Wall Street firms - the merger of Citicorp with Salomon Smith Barney (via the Travelers Group) being a case in point. Market observers have noted that this development may have exacerbated the potential for conflicts of interest. Also, stock exchanges in the US (and in many other countries) relaxed listing requirements enabling firms with limited track records to launch IPOs. So it is entirely possible that empirical results obtained with data from the 1990s (and particularly the late 1990s) may not carry over to earlier periods - the Loughran 
and Ritter (2002b) paper clearly suggests this in the context of IPO underpricing and the underlying factors. ${ }^{15}$

We believe that the IPO aftermarket is a fertile area for empirical analysis. As the finance literature embraces a more nuanced view of market efficiency, there may be unique opportunities to test the predictions of various theories that admit psychological biases in investor behavior. The late 1990s will also afford researchers the ability to gain insights into how investor biases can be exploited by opportunistic agents (be they financial intermediaries or insider-managers) in a bubble-like environment. Appropriately designed studies will not only deepen our understanding of market behavior but also inform the public policy debate in the areas of corporate governance, investor protection and securities law reform.

\section{Acknowledgements}

We thank two anonymous referees for insightful comments that greatly improved the paper. We also thank Sorin Codreanu for excellent research assistance. Any remaining errors are our own.

\section{References}

Aggarwal, R.K., Krigman, L., Womack, K.L., 2002. Strategic IPO underpricing, information momentum, and lockup expiration selling. Journal of Financial Economics 66, 105-137.

Arosio, R., Giudici, G., Paleari, S., 2000. Why do (or did?) Internet-stock IPOs leave so much "money on the table"? Unpublished manuscript.

Bandopadhyaya, A., Jaggia, S., 2001. An analysis of second time around bankruptcies using split population duration models. Journal of Empirical Finance 8 (2), 201-218.

Barberis, N., Shleifer, A., Vishny, R., 1998. A model of investor sentiment. Journal of Financial Economics 49, 307-343.

Benveniste, L.M., Spindt, P.A., 1989. How investment bankers determine the offer price and allocation of new issues. Journal of Financial Economics 24 (2), 343-361.

Brav, A., Gompers, P.A., 1997. Myth or reality? The long-run underperformance of initial public offerings: Evidence from venture and non-venture capital-backed companies. Journal of Finance 52, 1791-1821.

Carter, R.B., Dark, F.H., Singh, A.K., 1998. Underwriter reputation, initial returns and the long-run performance of IPO stocks. Journal of Finance 53 (1), 285-311.

Daniel, K., Hirshleifer, D., Subrahmanyam, A., 1998. Investor psychology and security market under- and over-reactions. Journal of Finance 53, 1839-1886.

Daniel, K., Hirshleifer, D., Teoh, S.H., 2001. Investor psychology in capital markets: Evidence and policy implications. Unpublished manuscript.

Delong, J.B., Shleifer, A., Summers, L., Waldmann, R.J., 1990. Positive feedback investment strategies and destabilizing rational speculation. Journal of Finance 45, 375-395.

Fama, E.F., 1998. Market efficiency, long-term returns and behavioral finance. Journal of Financial Economics 49, 283-306.

\footnotetext{
${ }^{15}$ In order to ensure at least in-sample stability, we ran a number of tests using estimation and holdout sub-samples within our overall sample. Results of these tests are not reported to preserve brevity but interested readers may obtain them from the authors.
} 
Fama, E.F., French, K.R., 1988. Permanent and temporary components of stock prices. Journal of Political Economy 96, 246-273.

Greene, W.H., 2000. Econometric Analysis, fourth ed. Prentice-Hall, Englewood Cliffs, NJ.

Grinblatt, M., Hwang, C.Y., 1989. Signaling and the pricing of new issues. Journal of Finance 44 (2), 393 420.

Hong, H., Stein, J.C., 1999. A unified theory of underreaction, momentum trading and overreaction in asset markets. Journal of Finance 54, 2143-2184.

Jain, B.A., Kini, O., 1994. The post-issue operating performance of IPO firms. Journal of Finance 49 (5), 1699-1726.

Lee, C.M.C., 2001. Market efficiency and accounting research: A discussion of 'capital market research in accounting' by S.P. Kothari. Journal of Accounting and Economics 31 (1-3), 233-253.

Lee, P.J., Taylor, S.L., Walter, S.W., 1996. Australian IPO pricing in the short and long run. Journal of Banking and Finance 20, 1189-1210.

Loughran, T., Ritter, J.R., Rydqvist, K., 1994. Initial public offerings: International insights. Pacific-Basin Finance Journal 2, 165-199.

Loughran, T., Ritter, J.R., 1995. The new issues puzzle. Journal of Finance 50, $23-51$.

Loughran, T., Ritter, J.R., 2002a. Why don't issuers get upset about leaving money on the table in IPOs? Review of Financial Studies 15 (2), 413-443.

Loughran, T., Ritter, J.R., 2002b. Why has IPO underpricing changed over time? Unpublished manuscript.

Morgenson, G., 2002. Regulators find another analyst with questionable reports. The New York Times, September 12.

Poterba, J.M., Summers, L.H., 1988. Mean reversion in stock returns: Evidence and implications. Journal of Financial Economics 22, 27-59.

Rock, K., 1986. Why new issues are underpriced. Journal of Financial Economics 15, 187-212.

Rubinstein, M., 2001. Rational markets: Yes or No? The affirmative case. The Financial Analysts Journal 57 (3).

Shiller, R.A., 1984. Stock prices and social dynamics. The Brookings Papers on Economic Activity (2), 457-510.

Welch, I., 1989. Seasoned offerings, imitation costs, and the underpricing of initial public offerings. Journal of Finance 44, 421-449. 